\title{
JUSTICIA RESTAURATIVA Y TÉCNICAS DE REPARACIÓN DEL DAÑO ECOLÓGICO EN EL DELITO MEDIOAMBIENTAL ${ }^{1}$
}

\section{RESTORATIVE JUSTICE AND DAMAGE REPAIR TECHNIQUES \\ IN ENVIRONMENTAL CRIME}

\author{
ANTONI CARDONA BARBER \\ Professor i investigador postdoctoral de Dret Penal \\ Universitat Autònoma de Barcelona \\ antonio.cardona@uab.cat
}

Fecha de recepción: 12 de septiembre de 2020 / Fecha de aceptación: 10 de noviembre de 2020

RESUMEN: El presente trabajo tiene por objeto estudiar el alcance de algunas de las herramientas vigentes en el Código penal para intentar mejorar la reparación del daño ecológico resultante de la comisión de un delito medioambiental. En concreto, se analizarán las capacidades que pueden tener las penas de multa, el instituto del decomiso y, algunas de las funciones de la responsabilidad civil ex delicto, para, desde una nueva mirada de justicia restaurativa, mejorar las expectativas de reparación del daño ante lesiones provocadas por la comisión de un delito ecológico.

RESUM: El present treball té per objecte estudiar l'abast d'algunes de les eines vigents en el Codi penal per intentar millorar la reparació del dany ecològic resultant de la comissió d'un delicte mediambiental. En concret, s'analitzaran les capacitats que poden tenir les penes de multa, l'institut del decomís $i$, algunes de les funcions de la responsabilitat civil ex delicto, per, des d'una nova mirada de justícia restaurativa, millorar les expectatives de reparació dels danys provocats per la comissió d'un delicte ecològic.

\footnotetext{
${ }^{1}$ Este trabajo se enmarca en el desarrollo del Proyecto $I+D+i$ "Reparación, Justicia Restaurativa y mediación en la delincuencia socioeconómica" (DER2017-84088-R) (IP: Dra. Mercedes García Arán).
} 
ABSTRACT: The purpose of this work is to study the scope of some of the tools in the Spanish Penal Code in order, from a new perspective of restorative justice, to try to improve the repair of ecological damage resulting from the commission of an environmental crime. Specifically, will be analyzed the capacities that fine penalties, the institute of confiscation and some of the functions of civil liability may have when improving the expectations of reparation for injuries caused by an ecological crime.

PALABRAS CLAVE: Delito ecológico - Delito medioambiental - Justicia restaurativa - Penas de multa - Decomiso - Responsabilidad civil - Reparación - Restauración.

PARAULES CLAU: Delicte ecològic - Delicte mediambiental - Justícia restaurativa - Penes de multa - Decomís - Responsabilitat civil - Reparació Restauració.

KEY WORDS: Ecological crime - Environmental crime - Restorative justice - Fine penalties - Confiscation - Civil liability - Reparation - Restoration.

SUMARIO: I. Cuestiones introductorias. 1. Las sanciones reparadoras como posibles instrumentos de justicia restaurativa en los delitos ecológicos 2. Requisitos de la tesis propuesta: una necesaria visión "maximalista" de la justicia restaurativa. 3. Excurso: ¿Están tutelados los intereses de las víctimas en el sistema penal español? II. La utilidad reparadora de las penas pecuniarias. 1. Algunas cuestiones generales sobre las penas permitidas. 2. La posible función reparadora de la pena de multa en el delito medioambiental. III. La posible utilidad restaurativa del decomiso. 1. Algunos apuntes generales del decomiso. 2. La posible función restaurativa del decomiso en el delito medioambiental. IV. La utilidad reparadora del artículo 112 del Código penal. V. Algunas medidas reparadoras previstas en la Parte especial del Código penal. VI. Conclusiones.

\section{CUESTIONES INTRODUCTORIAS}

\section{Las sanciones reparadoras como posibles instrumentos de justicia restaurativa en los delitos ecológicos}

Durante las últimas décadas, en varios países, y dentro de las corrientes de la conocida como justicia restaurativa, se han ido planteando una serie de propuestas alternativas a los modelos tradicionales de resolución de conflictos 
penales ${ }^{2}$, cuyos principales objetivos han sido (y son) favorecer la reparación del daño padecido por las víctimas del delito $\mathrm{y}$, mejorar su protagonismo en el transcurso del procedimiento penal ${ }^{3}$. A tal fin los sistemas de justicia restaurativa han canalizado sus respuestas a través de los conocidos como procesos restaurativos, procesos que facilitan encuentros participativos donde, víctimas y victimarios, intentan alcanzar algún tipo de acuerdo reparador ${ }^{4}$.

En este sentido, el desarrollo pormenorizado de las cuestiones sobre las diferentes tipologías o conceptualizaciones de las corrientes de justicia restaurativa desbordaría el objeto concreto de este artículo, y, por ello, por cuestiones de espacio y sistematización, aviso al lector que en las páginas siguientes no encontrará un tratamiento de la dicotomía referida.

Ahora bien, si analizamos los instrumentos diseñados en las corrientes de justicia restaurativa sí veremos cómo éstos están especialmente pensados para resolver los conflictos dimanantes de los delitos tradicionales, es decir, aquellos tipos penales con bienes jurídicos individuales y víctimas concretas identificables. En cambio, el sistema de encuentros participativos, método prototípico de las escuelas de justicia restaurativa, presenta algunos inconvenientes cuando se enfrenta a los conflictos nacidos a raíz de la comisión de delitos con estructura compleja: tipos penales con bienes jurídicos colectivos y posibles víctimas difundidas, como ocurre, concretamente, en la estructura típica del delito medioambiental.

En este contexto, el delito medioambiental, previsto en el artículo 325 del Código penal, castiga al que, contraviniendo las leyes $u$ otras disposiciones de carácter general protectoras del medio ambiente, provoca o realiza actuaciones que causan o puedan causar daños sustanciales en la calidad del aire, del suelo, de

\footnotetext{
${ }^{2}$ Entre muchos otros ver TAMARIT SUMALLA, J.M: "La justicia restaurativa: concepto, principios y marco teórico", en Tamarit (Coord.) La justicia restaurativa: desarrollo y aplicaciones, Granada, Comares, 2012; o, también, SHAPLAND, J: "Implications of growth: Challenges for restorative justice", en International Review of Victimology, 2014, p. 113.

${ }^{3}$ En este sentido, por ejemplo, GARCíA ARÁN señala que: "En la segunda mitad del siglo XX se produjo lo que ha sido denominado movimiento de redescubrimiento de la víctima, genéricamente dedicado a reconocer los derechos de las víctimas de los delitos y, en ocasiones, a otorgarles un mayor protagonismo en el proceso penal": GARCÍA ARÁN, M, "Reparación a la víctima y mediación en la delincuencia económica", en Un Derecho penal comprometido, libro homenaje al Dr. Gerardo Landrove Díaz, Valencia, Tirant Lo Blanch, 2011, p. 449.

${ }^{4}$ Entre otros muchos otros ver GORDILLO SANTANA, L.F.: La justicia restaurativa y la mediación penal, lustel, Madrid, 2007; o, BARONA VILAR, Mediación penal. Fundamento, fines y régimen jurídico. Valencia, Tirant lo Blanch, 2011, pp.144-149.
} 
las aguas, de los animales o de las plantas. Pues bien, como es obvio, cuando se consuma una lesión medioambiental, subsumible en el artículo 325 del Código penal, los efectos lesivos afectan a un número indeterminado y casi inacabable de víctimas difundidas y, por tanto, las técnicas de reparación propuestas y diseñadas en las escuelas de justicia restaurativa (encuentros bilaterales entre víctimas y victimarios conducíos por un facilitador) deberán, cuanto menos, repensarse.

De todos modos, lo anterior no significa que siempre que nos enfrentemos a delitos con bienes jurídicos colectivos debamos renunciar a la realización de procedimientos participativos entre víctimas y victimarios. Así, por ejemplo, podríamos destacar la publicación del proyecto de investigación "Victims and Corporations, Legal Challenges and Empirical Findings"5, en cuyo capítulo noveno AERTSEN, con la ayuda de la figura de la "víctima sustituta" o el "representante de la comunidad", apuesta por seguir utilizando el recurso de los encuentros participativos en los delitos corporativos causantes de daños comunitarios, señalando, específicamente para los delitos ecológicos, que los intervinientes en dichos encuentros deberían ser capaces de superar la visión antropocéntrica del mundo y enfocar el encuentro a la luz de una nueva mirada "ecocéntrica" del bien jurídico lesionado 6 .

También, al respecto de la víctima sustituta o sobre la intervención del representante de la comunidad, puede destacarse el reciente trabajo de RODRÍGUEZ PUERTA, autora que defiende la necesidad de seguir apostando por los encuentros participativos de justicia restaurativa, también ante la comisión de tipos penales con bienes jurídicos supraindividuales y víctimas colectivas. Para ello, no obstante, la autora advierte que será necesario redefinir el concepto de daño colectivamente padecido y, después, saber seleccionar correctamente a los individuos que vayan a intervenir en los encuentros participativos en nombre o representación de la comunidad afectada por el delito

\footnotetext{
5 <https://asgp.unicatt.it/asgp-VictimsCorporations Ebook 2018.pdf>, enlace donde se da cuenta del resultado del proyecto de investigación "Victims and Corporations. Implementation of Directive 2012/29/EU for Victims of Corporate Crimes and Corporate Violence" dirigido por, entre otros, GABRIO FORTI, y finaciado por el programa de la Unión Europea JUST/2014/JACC/AG/VICT/7417 [última consulta 25 julio 2020].

${ }^{6}$ AERTSEN, I.: "Restorative justice for victims of corporate violence", en FORTI, G. (Ed.): Victims and corporations. Legal Challenges and Empirical Findings, Wolters Kluwer, CEDAM, Milano, 2018, p. 249
} 
cometido, cuestión capital para que el acuerdo finalmente alcanzado revista suficiente legitimidad ante el grupo social lesionado 7 .

Ahora bien, más allá de las interesantes aportaciones señaladas en los párrafos anteriores, a mi juicio, la idiosincrasia propia de los tipos penales medioambientales exige que seamos capaces de encontrar otros instrumentos reparadores que, más allá de los encuentros participativos de la justicia restaurativa, también puedan servir para mejorar (o al menos coadyuvar) a la mejor reparación y restauración posible del daño provocado tras la comisión de un delito ecológico.

Así, por ejemplo, cuando la falta de voluntad de alguna de las partes impida la realización de los referidos encuentros participativos entre víctimas y victimarios, o bien, cuando la naturaleza del bien jurídico lesionado tenga un alcance global y transversal que afecte a una comunidad indeterminada de personas (como ocurre en el delito ecológico) la restauración y reparación de las víctimas también podría buscarse a través del concurso de algunas de las "sanciones reparadoras" previstas en el código penal.

En concreto, y tal y como desarrollaré a lo largo de este escrito, entiendo que pueden utilizarse las penas pecuniarias, el instituto del decomiso, y algún punto de la responsabilidad civil ex delicto para, a través de una nueva mirada de justicia restaurativa, coadyuvar a la mejor reparación posible del bien jurídico atacado, y, con ello, colmar el principal objetivo reparador de la justicia restaurativa, sin tener que forzar inescindiblemente algún tipo de encuentro participativo. Esta es la tesis principal del presente artículo y en las páginas siguientes intentaré fundamentar su argumentación.

\section{Requisitos de la tesis propuesta: una necesaria visión "maximalista" de la justicia restaurativa}

Debe señalarse, ante todo, que en la actualidad no contamos con una conceptualización única de justicia restaurativa ${ }^{8}$. Así, si bien las primeras

\footnotetext{
${ }^{7}$ RODRÍGUEZ PUERTA, MJ: "El derecho de las víctimas colectivas a participar en encuentros restaurativos. Un análisis a partir de algunos delitos económicos", en Revista Electrónica de Ciencia Penal y Criminología, "artículo en prensa".

${ }^{8}$ Actualmente las teorías de justicia restaurativa discurren por distintas corrientes con modelos reparadores singulares. Así se señala, por ejemplo, en el Manual sobre programas de justicia restaurativa, editado por la Oficina de las Naciones Unidas contra la droga y el delito, donde se
} 
formulaciones de justicia restaurativa nacieron de fuentes anglosajonas, con apoyos técnicos esencialmente criminológicos, y de marcada tendencia utilitarista, actualmente algunas de las nuevas aportaciones técnico-jurídicas están propiciando una suerte de reformulación o, como mínimo, moderación, de algunas de las políticas inicialmente reclamadas ${ }^{9}$.

En este sentido, por ejemplo, WALGRAVE señala que en la actualidad existen dos bandos opuestos sobre la posible conceptualización de la justicia restaurativa, aquellos que anteponen el proceso restaurativo frente a aquellos que priman los resultados restaurativos ${ }^{10}$. En concreto, este autor asegura que la mayoría de los defensores de la justicia restaurativa se juntan en el primer grupo bajo el enunciado de PAUL McCOLD a saber: "The essence of restorative justice is not the end, but the means by which resolution is achieved ${ }^{11}$ ". Así, según este primer grupo de investigadores, la esencia de la justicia restaurativa sería nada más y nada menos que facilitar un proceso restaurativo, a saber: el intento de juntar a víctimas y victimarios para que éstos pudieran desarrollar un encuentro participativo mediante el cual se intentaran alcanzar acuerdos reparadores.

Con ello, cabría llegar a la siguiente conclusión: la posible utilización de recursos sancionadores penales como métodos alternativos y/o complementarios de reparación, más allá de los sistemas de encuentros participativos, solamente

apunta que la justicia restaurativa es "un concepto evolutivo que ha generado diferentes interpretaciones en diferentes países, respecto al cual no hay siempre un consenso perfecto": $<$ https://www.unodc.org/documents/justice-and-prison-

reform/Manual sobre programas de justicia restaurativa.pdf> [última consulta 21 de febrero de 2020].

De todos modos, TAMARIT SUMALLA señala los puntos sobre los cuales existe un amplio conceso internacional respecto de un programa que exprese un "espíritu restaurativo" en: TAMARIT SUMALLA J.M: "El necesario impulso de la Justicia restaurativa tras la Directiva europea de 2012", en Ars luris Salmanticensis, Volumen 1, 139-160, junio 2013, p. 143.

9 Por ejemplo WALGRAVE, L: "Integrating criminal justice and restorative justice", en JOHNSTONE, G./ VAN NESS, D.N.: Handbook of Restorative Justice, Willan Publishing, 2007 o, SHAPLAND, J: "Implications of growth: Challenges for restorative justice", en International Review of Victimology, 2014. También desde una visión muy amplia, MAGLIONE, por ejemplo, considera que la justicia restaurativa refiere a "un campo dinámico de ideas, valores y principios producidos por académicos, defensores y profesionales, desde principios de la década de 1980, sobre por qué y cómo tratar los delitos": MAGLIONE, G: "The political rationality of restorative justice" en, Theoretical Criminology, 2019, p. 547.

10 WALGRAVE, L: "Investigating the Potentials of Restorative Justice Practice", en, Washington University Journal of Law \& Policy, 2011, pp. 95 y ss.

${ }^{11}$ McCOLD, P: "Paradigm Muddle: The Threat to Restorative Justice Posed by Its Merger whit Community Justice", en, Contemporary Justice Review, Vol 7, 2004, p.13; literalmente: "la esencia de la justicia restaurativa no es el fin, sino el medio por el cual se logra la resolución". 
podrían considerarse herramientas de justicia restaurativa si contásemos con un concepto amplio de la misma.

En este contexto, y a mi juicio acertadamente, WALGRAVE defiende que la justicia restaurativa no puede reducirse a una mera cuestión procedimental. En concreto, este autor defiende, desde un enfoque "maximalista" de la justicia restaurativa, que el valor de esta nueva mirada de justicia penal no debe buscarse en el tipo de procedimiento utilizado (tradicionalmente encuentros participativos entre víctimas y victimarios), sino, en los objetivos y resultados reparadores concretamente alcanzados ${ }^{12}$.

Convengo con el precitado autor. Piénsese, en primer lugar, que ningún procedimiento puede valorarse sin antes conocer sus objetivos: los procedimientos sirven de instrumento a determinados resultados, también en la justicia restaurativa. Lo anterior, evidentemente, no significa que cualquier fin justifique cualquier medio, pero, el valor de la justicia restaurativa no se encuentra en qué tipo de procedimiento restaurativo vaya a utilizarse, o qué acuerdos reparadores entre víctimas y victimarios vayan a intentarse. El valor de la justicia restaurativa se encuentra en qué resultados reparadores puedan alcanzarse ${ }^{13}$.

En este sentido, en el campo del common law, donde los márgenes dispositivos jurisdiccionales son mucho más generosos que los límites previstos en el sistema del civil law (algo que, a mi juicio, no es precisamente una virtud del sistema anglosajón), las experiencias prácticas acumuladas en los últimos años han dado pie a distintas publicaciones que valoran las técnicas restaurativas en casos de delincuencia corporativa con víctimas colectivas. Por ejemplo, SPALDING, desde una interesante visión de derecho penal internacional, critica que los fondos económicos recibidos por el Estado, tras la condena de una empresa por delitos socioeconómicos transnacionales, no sean destinados a la

\footnotetext{
12 WALGRAVE, L: "Investigating the Potentials of Restorative Justice Practice", en, Washington University Journal of Law \& Policy, 2011, pp. 95 y ss.

${ }^{13}$ En este sentido, WALGRAVE señala literalmente que: "a sanction imposed in order to partially repair a victim's harm and feelings of safety in the community may in some circumstances be considered in a restorative justice perspective": WALGRAVE, L: "Investigating the Potentials..." Ob.cit, p. 96. También, muy extensamente sobre las funciones de las sanciones como instrumentos reparadores ver ALASTUEY DOBÓN, C.: La reparación a la víctima en el marco de las sanciones penales, Tirant lo Blanch, Valencia, 2000.
} 
reparación de los daños soportado por las comunidades directamente afectadas por los delitos cometidos ${ }^{14}$. $\mathrm{O}$, entre otros, GABBAY, desde una perspectiva de justicia restaurativa, y en el campo de los delitos de cuello blanco, valora la oportunidad de evitar las penas de prisión para favorecer las condenas a trabajos en benéfico de la comunidad ${ }^{15}$.

En España es quizá NIETO MARTíN el autor que más ha trabajado y estudiado los instrumentos sancionadores que, desde un nuevo enfoque de justicia restaurativa, podrían utilizarse para mejorar las expectativas de reparación del daño provocado sobre un bien jurídico colectivo tras la comisión de un delito socioeconómico, analizando, entre otras cuestiones, las posibilidades reparadoras que, respecto de las penas económicas o los trabajos en beneficio de la comunidad, se les han encontrado en otros sistemas jurídico-penales ${ }^{16}$.

En este contexto, y en línea de continuidad con lo trabajado por al precitado autor, considero que en el campo del derecho penal medioambiental deben priorizarse aquellos instrumentos sancionadores que cuenten con algún contenido restaurativo o reparador, postergándose aquellos otros que solamente tengan una mirada retributiva ${ }^{17}$. En concreto, entiendo que, ante la comisión de tipos penales medioambientales, cuando menos para garantizar la restauración simbólica del bien jurídico atacado ${ }^{18}$, siempre que defendamos una visión maximalista de la justicia restaurativa, la plena reparación del daño cometido

\footnotetext{
${ }^{14}$ SPALDING, ANDREW, B: "Restorative Justice for Multinational Corporations", en Ohio State Law Journal, 2015, pp. 358 y ss.

${ }^{15}$ GABBAY, ZVI. D: "Exploring the Limits of the Restorative Justice Paradigm: Restorative Justice and White-Collar Crime", en Cardozo School of Law Journal of Conflict Resolution, 2012, pp. 421 yss.

${ }^{16}$ Vid. NIETO MARTÍN, A: "Autorregulación, "compliance" y justicia restaurativa", en ARROYO JIMÉNEZ, L; NIETO MARTÍN, A (Dir.): Autorregulación y sanciones, Aranzadi, Navarra, 2015; y, NIETO MARTÍN, A.: "Empresas, víctimas y sanciones restaurativas: ¿Cómo configurar un sistema de sanciones para personas jurídicas pensando en sus víctimas?", en HOYOS SANCHO, M. La víctima del delito y las últimas reformas penales, Aranzadi, Navarra, 2017, en cuya página 319 y ss. el autor cita y propone experiencias que han sido desarrolladas en otros países, en especial Estados Unidos, como las condenas a empresas a trabajos en beneficio de la comunidad o, también, las posibles penas pecuniarias en beneficio de la comunidad, instrumentos que, si bien adaptados al sistema español, más adelante defenderé como posibles vías alternativas para mejorar las expectativas de reparación del daño medioambiental.

17 También ver al respecto ver WALGRAVE, L: "Integrating criminal justice...", ob.cit, p. 565; o también, más recientemente, WALGRAVE, L: "Investigating the Potentials of Restorative..." ob.cit, pp. 95 y ss.

${ }^{18}$ En este sentido NIETO MARTÍN señala que: "La orientación amplia de la reparación hace que sean absolutamente posibles reparaciones simbólicas, en caso de bienes jurídicos supraindividuales como los que se tutelan en buena parte del Derecho penal económico": NIETO MARTíN, A: "Empresas ..." ob.cit, p. 326.
} 
podría buscarse a través de algunos instrumentos penales con cierto contenido sancionador, siempre que éstos, no obstante, fueran esgrimidos a través de un nuevo enfoque ecocéntrico y reparador.

En definitiva, apostando por una visión amplia de la justicia restaurativa, postergando, cuando así sea necesario, el procedimiento restaurador ante el mejor objetivo reparador, en las siguientes paginas estudiaré cómo pueden utilizarse las penas de multa, la técnica del decomiso y, algún instrumento concreto previsto en el sistema de responsabilidad civil ex delicto, para mejorar las expectativas de reparación del daño en delitos medioambientales, colmándose, asimismo, algunos de los objetivos de la justicia restaurativa, sin tener que renunciar, no obstante, al carácter público e indisponible de la respuesta jurídico-penal estatal ${ }^{19}$.

\section{Excurso: ¿Están tutelados los intereses de las víctimas en el sistema penal español?}

Cabe observar que, a nivel internacional, y dentro de las corrientes de justicia restaurativa, se está imponiendo la idea de que debe mejorarse el papel de las víctimas dentro del procedimiento penal ${ }^{20}$. Posiblemente las primeras alegaciones en este sentido, muy críticas con el sistema penal en general y el papel dado a la víctima en particular, se podrían encontrar en las obras de CHRISTIE $^{21}$ o de ZEHR ${ }^{22}$. En concreto, en estas líneas de pensamiento no solamente se señala que la doctrina no se ha interesado suficientemente por las víctimas del delito, las cuales, se han visto históricamente marginadas ante las preocupaciones que sí han despertado los victimarios ${ }^{23}$ sino que, incluso, se

\footnotetext{
${ }^{19}$ En este sentido, GARCÍA ARÁN critica que, para la mayoría de los teóricos defensores de la justicia restaurativa, al menos en su versión más ortodoxa, el carácter público de la relación jurídico-penal entre el Estado y el delincuente es "un anacronismo que se puede superar": GARCÍA ARÁN, M: "Reparación a la víctima...", ob.cit, p. 106

${ }^{20}$ MIR PUIG, S: Derecho Penal, Parte General, Barcelona, Editorial Reppertor, 2016, p. 49.

${ }^{21}$ Por ejemplo CHRISTIE, N: "Conflicts as Property", en The British Journal of Criminology,1977.

${ }^{22}$ Ver, por ejemplo, ZEHR, H: Changing lenses: a new focus for Crime and Justice, Scottsdale, PA, Herald Press, 1990; o ZEHR, H: "Retributive Justice, Restorative Justice", en New Perspectives on Crime and Justice, Occasional paper of the MCC Canada Victim Offenders Ministries Program, 1985, en cuya página 6 y ss. se señalaba rotundamente que el sistema de justicia criminal no funciona para las víctimas ni se preocupa por sus necesidades.

${ }_{23}$ También ver a LEMLEY ELLEN C: "Designing Restorative Justice Policy: An Analytical Perspective", en Criminal Justice Policy Review, Vol.12, Number 1, March, 2001, p. 44, donde en concreto se señala que: "Currently, victims and communities play no widespread active role in the justice system".
} 
afirma que las necesidades de los perjudicados del delito nunca han sido tenidas en cuenta por parte del legislador, quedando marginadas a cuestiones secundarias dentro del procedimiento penal.

No obstante, a mi juicio, esta pretendida marginación de la víctima en el proceso penal no se observa en el sistema español, no, al menos, de forma flagrante. En cuanto a la cuestión procesal, la Ley de Enjuiciamiento Criminal no solamente permite la libre personación de la víctima como parte activa del proceso, sino que, incluso, se le confiere la posibilidad de pedir penas e indemnizaciones muy superiores a las eventualmente solicitadas por parte del Ministerio Fiscal, lo cual, evidencia que en España los perjudicados y ofendidos pueden participar activamente y con plena autonomía en el procedimiento penal.

Además, más allá de la norma rituaria, la norma sustantiva penal también contiene varios instrumentos que, de forma razonable, buscan favorecer y facilitar la indemnización de las víctimas, y, por ello, no es cierto que el sistema penal se haya "olvidado" sistemáticamente de las necesidades reparadoras de los ofendidos por el delito ${ }^{24}$. Por ejemplo:

(i) Por medio del artículo $21.5 \mathrm{CP}$ se fomenta la reparación del daño causado a la víctima elevándola a la categoría de atenuante de la pena, en la práctica judicial muchas veces considerada como como muy cualificada.

(ii) También se ánima al delincuente a indemnizar a las víctimas a través de lo dispuesto en el artículo 80 del CP, precepto que permite suspender las penas inferiores a los dos años de prisión si el delincuente primario se ha responsabilizado de pagar la responsabilidad civil del delito cometido.

(iii) También debe recordarse que el artículo 126 del Código penal impone una prelación favorable a los perjudicados del delito, en el sentido de que los pagos realizados por el condenado se destinarán, primero de

\footnotetext{
${ }^{24}$ En esta línea, no solamente discutiendo la pretendida mejor atención de la víctima en los sistemas de justicia restaurativa, sino, incluso, tildando de mitos sus principales postulados, ver a KATHLEEN DALY: "Restorative justice, The real story", en Punishment \& Society, 2002.
} 
todo, a reparar el daño y pagar las indemnizaciones de las víctimas del delito 25 .

(iv) También, el artículo 127 octies, tercer apartado, dispone que los bienes decomisados deberán utilizarse para indemnizar a las víctimas, y, solamente si no concurren víctimas pendientes de reparación, podrán destinarse a otros fines.

(v) Incluso, por medio del artículo $130.5 \mathrm{CP}$ la política criminal ha decidido que, en algunos delitos, el perdón del ofendido excluirá la responsabilidad penal del ofensor, perdón que, normalmente, se conseguirá después de que se hayan visto satisfechas las expectativas económicas de las víctimas.

(vi) A mayor abundamiento, el artículo 72.5 de la Ley Orgánica 1/1979, de 26 de septiembre, General Penitenciara, señala que "la clasificación o progresión al tercer grado de tratamiento requerirá, además de los requisitos previstos por el Código Penal, que el penado haya satisfecho la responsabilidad civil derivada del delito, considerando a tales efectos la conducta efectivamente observada en orden a restituir lo sustraído, reparar el daño e indemnizar los perjuicios materiales y morales (...)".

Más allá de todo lo anterior, y justificándose en la pretendida marginación de la víctima, por parte de algunas corrientes de justicia restaurativa se han propuesto algunos mecanismos reparadores que deben criticarse. Me refiero, en concreto, al método que defiende que las víctimas deben disponer plenamente del conflicto para, si lo estiman conveniente, llevar a cabo una negociación libre con el victimario, mediante la cual puedan acordarse todo tipo de pactos indemnizatorios a cambio de posibles exoneraciones penales de obligada aceptación por parte de la autoridad judicial ${ }^{26}$. En este sentido, considero que

25 Subsidiariamente, los pagos realizados se imputarán en el orden siguiente: (i) a la indemnización al Estado por el importe de los gastos que se hubieran hecho por su cuenta en la causa: (ii) a las costas del acusador particular o privado cuando se impusiere en la sentencia su pago; (iii) a las demás costas procesales, incluso las de la defensa del procesado, sin preferencia entre los interesados; $y$, finalmente, (iv) al pago de la multa.

26 En la línea de pensamiento crítico iniciada por CHRISTIE (y no compartida en esta contribución) se defiende, incluso, que el Estado ha "robado" a las víctimas la propiedad de su conflicto y su derecho a reivindicar y solucionar libremente el ataque por ellas sufrido: CHRISTIE, N: "Conflicts ...", ob.cit. 
este tipo de "justicia penal privada" no solamente permitiría que los acusados "comprasen" atenuantes, eximentes, o perdones, sino que, incluso, comportaría una obscena desigualdad de trato judicial, entre los pudientes y los desdichados: solamente aquellos individuos con una capacidad económica suficiente podrán permitirse el lujo de pagar y librarse de la acción penal ${ }^{27}$.

Además, estos pactos entre víctimas y victimarios, con capacidad de influencia definitivas sobre la pena, pondrían en serio riesgo la prevención general negativa en aquellos delitos donde los autores dispusieran de una capacidad económica suficiente para poder "comprarse" la libertad. En este contexto, considero que la función intimidatoria de la pena en la delincuencia empresarial no es una función menor, todo lo contrario: la realidad constante de los hechos la revelan como una indudable necesidad social a la cual no podemos renunciar.

Es quizá este lugar donde mejor se manifiesta la idea de que los sistemas de justicia restaurativa y justicia tradicional (o mal llamada "justicia retributiva": hace muchos años que el Derecho penal contemporáneo se justifica principalmente en la prevención y no en la retribución) no son ni sistemas incompatibles ni polos opuestos $^{28}$, sino que cada uno de ellos puede tener su espacio y justificación práctica $^{29}$.

Entiéndase que no estoy en contra de cualquier tipo de pacto procesal entre víctimas y agresores. Ahora bien, cualquiera que haya tenido la oportunidad de ejercer la abogacía penal, y se haya visto en la tesitura de negociar pactos con alguna de las partes, puede ser consciente que los acuerdos privados, cuando la cuestión todavía está sub iudice, contaminan inescindiblemente el proceso penal. Por ello, considero que los pactos de naturaleza económica alcanzados dentro de los procesos restaurativos o encuentros participativos, con capacidad

\footnotetext{
${ }^{27}$ Por ejemplo, ver SOLETO, H/ GRANÉ A: La reparación económica a la víctima en el sistema de justicia, Madrid, Dykinson, 2019, p. 530, donde se señala que si la reparación que pudiese dar pie a beneficios penológicos únicamente fuera una cuestión económica se "trasladaría un mensaje de impunidad a aquellas clases sociales más pudientes".

${ }^{28}$ Incluso, ZEHR, uno de los pensadores más críticos con el sistema penal tradicional, revisa sus posiciones iniciales para acabar aceptando que: "The contrasting models that I outlined there retributive justice vs. restorative justice have been widely adopted in the field. Those charts remain a useful analytical or critical tool, but on the philosophic or theoretical level, I no longer see restoration as the polar opposite of retribution".: ZEHR, H/ GOHAR, A: The little book of Restorative Justice, Good Books, 2003, p. 11.

${ }^{29}$ Entre otros, sobre la compatibilidad de ambos sistemas, ver DANIELS, G: "Restorative justice: Changing the paradigm" en Probation Journal, The Journal of Community and Criminal Justice, 2013, p. 311.
} 
de influencia sobre la pena, deberían posibilitarse solamente en aquellos delitos considerados de menor gravedad. En los otros casos, los fines preventivo generales y especiales del Derecho penal, conseguidos a través de la amenaza y ejecución de las penas, deben hacer postergar las eventuales necesidades económicas de las víctimas.

Evidentemente en este campo, el de la satisfacción de la víctima y la reparación del daño, caben plantearse mejoras y perfecciones. De hecho, considero que algunos de los instrumentos ideados dentro de las corrientes de justicia restaurativa, como los encuentros participativos, o los convenios entre partes sometidos a validación judicial, pueden ayudar a mejorar la intervención de las víctimas en el proceso penal y, también, mejorar sus expectativas a la hora de fomentar una completa reparación del daño.

Ahora bien, como ya se ha dicho más arriba, estos instrumentos están especialmente pensados para resolver los conflictos dimanantes de los delitos tradicionales, es decir, aquellos tipos penales con bienes jurídicos individuales y víctimas concretas identificables. En cambio, en el campo de la delincuencia socioeconómica en general, y, en particular, en aquellos delitos, como los ecológicos, donde se tutelan intereses colectivos, cuya consumación podría lesionar a un grupo de víctimas difundidas, los instrumentos clásicos de justicia restaurativa deberán ser repensados.

\section{LA UTILIDAD REPARADORA DE LAS PENAS PECUNIARIAS}

\section{Algunas cuestiones generales sobre las penas permitidas}

La pena, en cuanto consecuencia jurídica del delito, ha sido uno de los temas que más ha preocupado a la política criminal de los últimos doscientos años ${ }^{30}$. Es más, uno de los cambios jurídico-penales de mayor impacto ha sido, precisamente, el operado a partir de la nueva teorización de las penas admisibles en el Estado social contemporáneo. En este sentido, gracias a los esfuerzos de los pensadores ilustrados del Siglo XIX, las legislaciones decimonónicas superaron el marco penológico barbárico, característico del Anciem Régime, y

\footnotetext{
${ }^{30}$ MIR PUIG, S: Derecho Penal ..., ob.cit, p. 693
} 
apostaron por un sistema de Derecho penal ilustrado garantista con los principios de taxatividad, proporcionalidad y humanidad de las penas.

En concreto, puede decirse que las ideas de BECCARIA 31 "constituyeron la antesala del derecho penal moderno ${ }^{32 " ~ y ~ s e n ̃ a l a r o n ~ a l g u n o s ~ d e ~ l o s ~ l i ́ m i t e s ~ q u e ~}$ deberían imponerse al poder punitivo Estatal. A mayor abundamiento, y en confluencia con lo anterior, se abrieron paso las nuevas teorías filosóficas de la pena, las cuales, favorecieron una cierta moderación penológica a la luz, primero, del sentido retribucionista proporcional de la pena (en las teorías absolutas) o, después, a través de la finalidad preventiva utilitaria de la misma (en las teorías relativas).

En este sentido, inicialmente se impusieron las concepciones absolutas retribucionistas, según las cuales, el mal infligido por la pena tenía como sentido la compensación del mal cometido por el delincuente. De este modo, ya fuera en base al imperativo categórico kantiano ${ }^{33}$, ya fuera a la luz del sentido de la retribución jurídica hegeliana ${ }^{34}$, la pena miraba al pasado, no al futuro: servía para retribuir al autor del delito cometido, siempre de forma proporcional al daño cometido $^{35}$. No obstante, en la actualidad puede observarse una posición doctrinal mayoritaria más favorable a los postulados de las tesis relativas, según las cuales, las penas cuentan con una finalidad utilitaria, de naturaleza preventiva, que justifica su imposición ${ }^{36}$.

\footnotetext{
${ }^{31}$ En especial las plasmadas en su obra "De los delitos y las penas", publicada en el año 1764.

32 BUSTOS RAMÍREZ, J: Prevención y Teoría de la Pena, Santiago de Chile, Editorial Jurídica Conosur, 1995, p.21.

${ }^{33}$ I. KANT: La metafísica de las costumbres (Metaphysik der Sitten) 1797, en especial pp.167 y ss, donde el filósofo prusiano justifica su moral retribucionista a partir de su clásico ejemplo de la isla.

${ }^{34}$ G. W. F. HEGEL: Principios de la filosofía del derecho o Derecho natural y ciencia política, ed. Edhasa, (1821) 2º edición, 1999, en cuya página 186 se señala que: "el delito debe ser eliminado no como la producción de un perjuicio, sino como lesión del derecho en cuanto derecho".

${ }^{35}$ Con algunas referencias interesantes en DURÁN MIGLIARDI, M: (2011) "Teorías absolutas de la pena: origen y fundamentos. Conceptos y críticas fundamentales a la teoría de la retribución moral de Immanuel Kant a propósito del neo-retribucionismo y del neo-proporcionalismo en el Derecho penal actual", en Revista de Derecho y Ciencias Penales №16 (91-113).

${ }^{36}$ De todos modos, actualmente se ha encontrado una cierta solución de compromiso en las teorías mixtas, las cuales, si bien consideran que la prevención es la principal finalidad de la pena, aceptan cierto grado de sentido retribucioncita como elemento necesario a su justificación. Así ROXIN, C: "Sentido y límites de la pena estatal" en Problemas básicos del Derecho Penal, Ed. Reus, Madrid, 1976; o, también, ROXIN, C: Derecho Penal. Parte General, Madrid, Civitas, 2006, pp. 95 a 104.
} 
Gracias a todo lo anterior, en las nuevas legislaciones, configuradoras del Derecho penal moderno, se fueron abandonado paulatinamente las penas capitales, las corporales, y, los trabajos forzados. En su sustitución los legisladores decidieron hacer descansar el nuevo protagonismo de la respuesta jurídico-penal en las penas privativas de libertad. De todos modos, acertadamente, la desescalada punitivista, si bien padeciendo un cierto movimiento pendular, ha continuado desarrollándose a lo largo de todo el siglo $X X$, periodo donde la mayoría de legislaciones comparadas han ido incorporado en sus ordenamientos penales algunas alternativas menos aflictivas $y$ estigmatizantes que la clásica pena de prisión.

En este sentido, si analizamos las penas específicamente previstas en el actual Código penal español veremos cómo las penas de multa son el recurso más utilizado por el legislador, solamente superado por la clásica pena de prisión ${ }^{37}$. Puede decirse, por tanto, que en la actualidad el uso de la pena de multa en el sistema jurídico-penal español es recurrente. Todo ello es una clara manifestación de las corrientes de modernización de las medidas penales referidas más arriba.

\section{La posible función reparadora de la pena de multa en el delito medioambiental}

En cuanto a la posible función reparadora de la pena de multa en los delitos ecológicos la propuesta que quiero plantear es la siguiente: en los delitos medioambientes el Estado, además de utilizar los instrumentos indemnizatorios tradicionales, podría intentar completar la reparación del bien jurídico ambiental lesionado con la ayuda del dinero de la multa (o, como mínimo, con parte del montante obtenido), destinándolo a financiar proyectos orientados a la protección, o la restauración, o la mejora, de los espacios naturales lesionados (o puestos en peligro) por el delincuente ecológico condenado.

De hecho, esta posible orientación restauradora de las penas de multa toma una mayor relevancia práctica cuando lo trabajamos en el marco de la

\footnotetext{
${ }^{37}$ Así, por ejemplo, MIR PUIG, S: Derecho Penal..., ob.cit, en cuya página 750 señala que: "Siguiendo el ejemplo de otras legislaciones recientes, como la alemana, la austríaca, la italiana y la francesa, el Derecho penal español ha querido conceder a la pena de multa un papel mucho más importante que el que le correspondía anteriormente".
} 
responsabilidad penal de las personas jurídicas. En este contexto, como es sabido, en España, a partir de la reforma operada por la Ley Orgánica 5/2010, se permite atribuir responsabilidad penal directamente a las personas jurídicas. En este sentido, las penas previstas para este tipo de entes están señaladas en el artículo 33.7 del Código penal, destacando, por encima del resto, las penas de multa.

Así, por ejemplo, en una lesión medioambiental, derivada de un delito ecológico, la indemnización civil pagada por la empresa condenada servirá, como máximo, para reparar una parte del daño cometido por aquélla: en este tipo de delitos los daños ecológicos normalmente son incalculables, apareciendo, incluso, después de la sentencia firme, nuevos resultados lesivos de la conducta ya condenada. Es más, recuérdese que, a la luz del esquema básico y tradicional de la responsabilidad civil indemnizatoria no punitiva, donde se paga sólo lo que se daña, el penado no deberá asumir mayor responsabilidad que la concretamente determinada en la Sentencia condenatoria.

Por ello, entiendo que sería muy razonable que el Estado utilizara el dinero ingresado por el pago de la multa para conseguir una mejor reparación, o protección, del bien jurídico atacado. Esta reparación podría llevarse a cabo, por ejemplo, contratando nuevos agentes forestales locales, invirtiendo en la conservación de los bosques y montes del lugar, expropiando nuevas zonas con vocación de espacios verdes protegidos, mejorando los sistemas de depuración y canalización de aguas municipales, etc.

Otro posible ejemplo: en el escenario de una construcción no autorizable, subsumible en un delito contra la ordenación del territorio en concurso con un delito medioambiental, además de la obligada restauración de la legalidad alterada, podría completarse la reparación del bien jurídico lesionado mediante el dinero de la multa, el cual, por ejemplo, podría utilizarse para financiar proyectos que tuvieran por objeto la mejora de los equipamientos públicos municipales, el reciclaje urbanístico de las zonas municipales degradadas, las obras de conservación de viales, la restauración de los edificios históricos locales, la construcción de nuevas viviendas de protección oficial, etc.

Es decir, para favorecer una restauración más completa del espacio natural atacado, o, como mínimo, de mayor impacto social, sobre todo en aquellos 
delitos ambientales donde los perjudicados del delito son una comunidad de individuos indeterminados, el Estado podría destinar el dinero obtenido a través de la pena de multa para favorecer la prevención general positiva del Derecho penal, mejorando para ello las expectativas restaurativas del lugar dañado.

A mayor abundamiento, debe subrayarse que la idea señalada en los párrafos anteriores, sobre la oportunidad y utilidad de destinar parte del montante recaudado por la pena de multa a funciones de reparación y restauración del interés ambiental atacado, no es una idea novedosa, al menos, en su estructura. Se copia aquí, simplemente, el sistema previsto en la Disposición adicional cuarta del Real Decreto Legislativo 6/2015, de 30 de octubre, por el que se aprueba el texto refundido de la Ley sobre Tráfico, Circulación de Vehículos a Motor y Seguridad Vial, donde se impone, específicamente, la obligación de que el importe recaudado a través de las multas administrativas de tráfico sea destinado a la financiación de políticas de seguridad vial, prevención de accidentes de tráfico y partidas de ayudas a las víctimas.

En el ordenamiento jurídico penal no se contempla una previsión similar. De hecho, los pagos de las penas de multa son ingresados en la cuenta común de depósitos y consignaciones judiciales, titularidad del Ministerio de Justicia, gestionada actualmente por la entidad Banco Santander. Así, el dinero pagado en concepto de multas penales se mezcla con los demás ingresos realizados a dicha cuenta y, sobre ellos, en cuanto a su posible destino o finalidad, no existe ningún tipo de obligación o previsión reglamentaria. Con ello, los gestores del Estado pueden utilizar dichos fondos de la manera que mejor se ajuste a las necesidades particulares del momento, dentro de su ideología política concreta. Ahora bien, ¿es posible una previsión análoga a la prevista en el ordenamiento jurídico administrativo para las multas de tráfico en el sistema de multas penales? Ciertamente, no todos los tipos delictivos permiten delimitar con la misma facilidad un catálogo de posibles acciones restaurativas. De todos modos, ejemplos como la defensa del medioambiente permiten abrir el debate sobre los beneficios de destinar el dinero de las multas penales a reparar y/o mejorar específicamente los objetos lesionados, o intereses sociales comprometidos, mediante los delitos ecológicos cometidos. 


\section{LA POSIBLE UTILIDAD RESTAURATIVA DEL DECOMISO}

\section{Algunos apuntes generales de la figura del decomiso}

Antes de abordar la cuestión del decomiso como posible instrumento reparador deben dejarse señaladas algunas de sus características típicas más generales, algo que, después, me ayudará a explicar cómo cabría utilizarse este instrumento para favorecer la reparación del daño ecológico a través de una nueva mirada de justicia restaurativa. En este sentido, en el actual Código penal español el decomiso presenta las siguientes formas:

(i) "El decomiso ordinario tradicional o directo", previsto en el artículo 127.1 del CP, donde se señala que toda pena que se imponga acarreará la pérdida de los efectos que del delito provengan y de los bienes, medios o instrumentos con los cuales se haya preparado 0 ejecutado el hecho criminal, así como de las ganancias provenientes del delito, cualesquiera que sean las transformaciones que hubieren podido experimentar.

(ii) “El decomiso en los delitos imprudentes", previsto en el artículo 127.2 del CP. Según se dispone en este precepto el juez podrá (no es una disposición imperativa) ordenar el decomiso cuando la pena del delito imprudente sea superior a un año de prisión.

(iii) "El decomiso ampliado", previsto en el artículo 127 bis del CP. Esta figura permite al juez o tribunal decomisar bienes del delincuente, distintos a los bienes directamente vinculados con el delito por el cual ha sido condenado, cuando se resuelva, a partir de indicios objetivos fundados, que esos bienes también provienen de una actividad delictiva, sin que sea necesario que ésta sea declarada probada en un procedimiento penal.

(iv) "El decomiso sin condena", previsto en el artículo 127 ter del CP. Esta figura se justifica en la idea de que el decomiso no es una pena, y que, por tanto, cabría el decomiso de los bienes incluso en aquellos casos donde no se pudiese condenar penalmente al delincuente ${ }^{38}$.

\footnotetext{
${ }^{38}$ En concreto, cabía el decomiso sin condena cuando: (a) el sujeto hubiese fallecido o sufriese una enfermedad crónica que impidiese su enjuiciamiento; (b) cuando existiera un riesgo cierto
} 
(v) "El decomiso por valor equivalente", previsto en el artículo 127.3 del CP. En este sentido, es posible imaginar un escenario donde, una vez decidido el decomiso de ciertos bienes, se revele la imposibilidad de su incautación, ya sea porque los bienes están escondidos 0 , han padecido algún tipo de depreciación en su valor. Pues bien, el decomiso por valor equivalente permite decomisar otros bienes del acusado por medio de los cuales quede compensado el valor de los bienes cuyo decomiso no haya sido posible materializar ${ }^{39}$.

(vi) "El decomiso contra intereses de terceros", previsto en el artículo 127 quater del CP. Este precepto regula dos escenarios distintos, dependiendo de si se quieren decomisar efectos y/o ganancias, o, si quieran decomisar otro tipo de bienes. En el primer escenario el precepto señala que procederá el decomiso cuando los efectos o ganancias hubieran sido adquiridos por el tercero con conocimiento de que éstos procedían de una actividad ilícita. Asimismo, en cuanto a los otros bienes, el Código penal determina que podrán ser decomisados cuando el adquiriente hubiera podido tener conocimiento de que estaba participando en un negocio cuyo objetivo era el de dificultar una incautación judicial.

En definitiva, el decomiso, con sus distintas formas, puede servir tanto para neutralizar los instrumentos utilizados para cometer el delito como para desapoderar al delincuente de los beneficios que hubiera obtenido a través del delito, evitándose con ello su enriquecimiento injusto. Esto último tiene una especial relevancia en la esfera de la delincuencia económica, sector de la

de que los hechos pudieran prescribir; (c) cuando el sujeto se encontrase en rebeldía y ello impidiese que los hechos pudieran ser enjuiciados dentro de un plazo razonable, o (d) que no se impusiera pena alguna por concurrir alguna causa de exención de responsabilidad criminal.

39 En ocasiones este tipo de decomiso puede llegar a tener un claro contenido punitivo que debería criticarse. En este sentido, se ha señalado que el fundamento del decomiso descansa en evitar el enriquecimiento ilícito del delincuente o en prevenir su peligrosidad futura. Ahora bien, cuando la incautación de los instrumentos mediante los cuales se hubiera perpetrado el delito no fuera posible porque éstos, por ejemplo, hubieran sido destruidos, de seguirse una interpretación literal del artículo 127.3 CP deberían decomisarse otros bienes (incluso lícitos) que vinieran a compensaran el valor equivalente de los objetos que, "por cualquier circunstancia" no hubiera podido ser decomisados. En estos escenarios, como acertadamente señala GARCíA ARÁN: "sustituir el objeto originariamente decomisable por otros de igual valor económico carece claramente del fundamento del comiso y lo convierte en una sanción pecuniaria basada exclusivamente en una cuantía económica": CÓRDOBA RODA, J/ GARCÍA ARÁN, M (directores): Comentarios al Código penal, Parte general, Barcelona, Marcial Pons, 2011, p, 958. 
criminalidad donde, en ocasiones, ante las importantes cantidades de dinero que están en juego, el catálogo de penas clásicas (prisión o multa) no siempre consigue una intimidación suficiente ${ }^{40}$.

\section{La posible función restaurativa del decomiso en el delito medioambiental}

En cuanto al decomiso, junto con las funciones tradicionales señaladas en el punto anterior, también puede defenderse, no solamente una función coadyuvante a la reparación clásica del daño sino, incluso, una función reparadora con vocación restaurativa más general y transversal, especialmente útil en escenarios de ataques medioambientales.

En este sentido piénsese que en el artículo 127 octies del CP se señala que, si no constan víctimas concretas pendientes de indemnización, el Estado destinará los bienes decomisados a los fines dispuestos legal o reglamentariamente. Esta previsión permite que el Estado, a través de los beneficios obtenidos con los bienes decomisados, y desde una óptica de justicia restaurativa, pueda fomentar políticas públicas reparadoras del tipo de intereses colectivos lesionados, ya sea para reparar parte del daño padecido por la sociedad, ya sea para mejorar la tutela y protección del interés colectivo atacado por el agresor.

De hecho, actualmente el sistema jurídico español acoge un ejemplo concreto y preciso de esta forma de entender los posibles fines de los bienes decomisados, me refiero a los delitos que favorecen el tráfico de drogas, cuyo bien jurídico, como se sabe (del mismo modo que en los delitos contra el medioambiente) es un interés colectivo que importa a una pluralidad de personas indeterminadas, a saber: la salud pública. Así, en España existe el Fondo de bienes decomisados por tráfico ilícito de drogas y otros delitos relacionados, regulado en la Ley 17/2003, de 29 de mayo, cuyos fines, a tenor de lo dispuesto en el artículo segundo, son, básicamente: (i) favorecer programas de prevención de toxicomanías, asistencia de drogodependientes e inserción social y laboral de éstos; (ii) intensificar y mejorar las actuaciones de prevención, investigación,

\footnotetext{
${ }^{40}$ En términos similares, por ejemplo, RODRíGUEZ PUERTA, autora que señala que: "Si lo que motivo el comportamiento delictivo fue la obtención de una ventaja personal o de un beneficio para su empresa, aparejar al hecho delictivo la perdida de dichas ventajas integra una contramotivación idónea para esta clase de delincuentes": RODRÍGUEZ PUERTA, MJ: "Modelos de prevención y sanción de la delincuencia económica. Perspectiva comparada", en La delincuencia económica. Prevenir y sancionar, GARCíA ARÁN, M (Dir.) Valencia, Tirant lo blanch, 2014, p. 386 y 387.
} 
persecución y represión de los delitos de tráfico de drogas, especialmente sufragando los gastos necesarios para la obtención de pruebas en la investigación de los delitos y los medios materiales para los órganos competentes en la represión; y, (iii) financiar, en general, la cooperación internacional en la lucha contra el tráfico de estupefacientes.

Pues bien, en este punto quiero proponer el estudio de una institución similar, pensada ahora para los delitos medioambientales (y por extensión para los delitos contra la ordenación territorial), delitos que, del mismo modo que los tipos penales que persiguen el tráfico de drogas, tutelan intereses de víctimas difundidas y protegen bienes jurídicos colectivos.

Así, por ejemplo, considero que sería perfectamente imaginable un Fondo de bienes decomisados por los delitos medioambientales y contra la ordenación territorial, por medio del cual, se facilitasen las ayudas financieras necesarias para, por ejemplo, sufragar programas de rehabilitación de espacios naturales, la conservación y mantenimiento del patrimonio histórico, artístico o cultural público y, la mejora e intensificación de las actuaciones de prevención, investigación, persecución y represión de los delitos contra la ordenación territorial, el medio ambiente, y la protección del patrimonio histórico, por ejemplo, sufragando los gastos necesarios para la obtención de pruebas en la investigación de éstos delitos ${ }^{41}$.

Finalmente, además de las cuestiones vinculadas al instituto del decomiso en general, creo que deben señalarse algunas menciones específicas a las capacidades reparadoras de la especialidad "decomiso sin condena". En este sentido, más arriba he explicado como el legislador, por medio de la reforma penal operada en el año 2015, ha previsto, en el artículo 127 ter del Código penal, la figura del decomiso sin condena, instrumento que permite nada más y nada menos que ordenar el decomiso de bienes, aunque no hubiera recaído una sentencia penal condenatoria.

\footnotetext{
${ }^{41}$ En este contexto, RODRIGUEZ PUERTA recuerda que: "la investigación y sanción de la delincuencia de cuello blanco, normalmente, genera unos gastos muy elevados. La inversión que debe realizar el sistema de justicia penal en la lucha e investigación de estos delitos no siempre soporta un examen económico. La recaudación derivada de la imposición de sanciones patrimoniales podría mitigar este inconveniente": RODRíGUEZ PUERTA, MJ: "Modelos de prevención..." ob.cit,, p. 386.
} 
En este sentido, la doctrina ha puesto de manifiesto los peligros que se le presentan a las escuelas de justicia restaurativa cuando el sistema no es capaz de "capturar" al delincuente, cuya participación se revela como un requisito sine qua non en todos los encuentros participativos entre víctimas y victimarios ${ }^{42}$. Ahora bien, desde una visión amplia de las teorías de justicia restaurativa, visión más centrada en el valor de los objetivos reparadores que en la sacralización de los procedimientos restaurativos, el hecho de no poder llevarse a cabo encuentros participativos no debería conllevar una renuncia del principal objetivo de la justicia restaurativa, a saber: la reparación y restauración del daño cometido por el delincuente ${ }^{43}$.

Así, considero que la figura del decomiso sin condena se presenta como un instrumento de cierta utilidad ya que, con éste, se permite al juez ordenar el decomiso de bienes cuando, entre otros supuestos, el encausado hubiese fallecido, sufriese una enfermedad crónica impeditiva o, cuando se encontrase en rebeldía, tres situaciones que, a su vez, también cercenarían la posibilidad de concertar encuentros participativos entre víctimas y agresores. Así, aunque no fuera posible cerrar el procedimiento penal principal, y con ello, no se pudiera obtener una condena penal, el instituto del decomiso sin condena posibilitaría la ejecución y realización de una serie de bienes que, una vez utilizados del modo propuesto en los párrafos anteriores, ayudarían a la reparación del daño y a la restauración del bien jurídico lesionado.

En definitiva, en este apartado lo que se propone es que se le imprima al instituto del decomiso una nueva mirada restaurativa, según la cual, los bienes decomisados sean utilizados por el Estado tanto para completar o mejorar la reparación los daños directamente cometidos por los delincuentes ecológicos, como, para financiar y tutelar todos aquellos medios que sean necesarios para

\footnotetext{
${ }^{42}$ Por ejemplo, LARSON, J/ HOWARD, Z recuerdan que: "Victims advocates have also criticized restorative justice programmes for only serving (thus empowering and engaging) victims when offenders have been caught and when offenders are willing to participate": LARSON, J; HOWARD, Z: "The ideas of engagement and empowerment", en JOHNSTONE, G, Handbook of Restorative Justice, Ed. Willam Publising, 2007, p. 49.

43 Sobre la importancia de la finalidad reparadora en la justicia restaurativa más allá de los encuentros participativos ver, entre otros, JOHNSTONE G/ W. VAN NESS, D: "The meaning of restorative justice", en JOHNSTONE, G and VAN NESS, D (editores): A Restorative Justice Reader. Text, sources, context, Willan Publishing, 2007, pp. 12 y 13.
} 
reforzar la protección de los bienes jurídicos ambientales más relevantes e importantes de nuestro sistema de convivencia.

\section{LA UTILIDAD REPARADORA DEL ARTÍCULO 112 DEL CÓDIGO PENAL}

Como se ha dicho a lo largo de este estudio, en la gran delincuencia socioeconómica empresarial, y, en particular, en los delitos contra el medioambiente, la reparación personal y completa de cada una de las víctimas afectadas por el delito es una tarea prácticamente imposible. Por ello, en este tipo de delincuencia, y cuando no puedan satisfacerse individualmente a cada uno de los perjudicados, la reparación del daño debe incluir una mirada restaurativa transversal y de mayor alcance valorativo, que sirva, muy especialmente, para mantener la credibilidad del sistema penal ante el grupo social y mantenga un objetivo reparador que alcance "a la restauración de las condiciones socioeconómicas alteradas por el delito $44 "$. De hecho, en línea con lo defendido por NIETO MARTÍN, aquí el objetivo reparador de las corrientes de justicia restaurativa debe entenderse en un sentido amplio, así: "No se trata solo de reparar el daño producido a la víctima, sino de forma más comprehensiva la totalidad de los efectos negativos que produce la conducta en la comunidad, grupo social o corporación en la que se ha cometido el delito ${ }^{45}$ ".

Más arriba, al tratar la cuestión de la pena de multa, o el instituto del decomiso, he señalado que, en el campo de los delitos ecológicos, a través de una nueva mirada de justicia restaurativa, cabría utilizarse el montante recaudado con las sanciones pecuniarias (o la realización de los bienes decomisados), para fomentar políticas reparadoras del bien jurídico medioambiental atacado ${ }^{46}$.

No obstante, y sin renunciar en ningún caso al objetivo reparador, debe señalarse que, en ocasiones, la imposición de una elevada pena de multa a una empresa puede lesionar otros intereses legítimos concurrentes. Así, por ejemplo, si a consecuencia de la multa impuesta la persona jurídica se viera abocada al cierre total o parcial de sus actividades empresariales, no solamente se

\footnotetext{
${ }^{44}$ GARCÍA ARÁN, M: "Reparación ...", ob.cit, pp. 472 y ss.

45 NIETO MARTíN, A.: "Autorregulación..." ob.cit, p. 122.

${ }^{46}$ Al respecto, ver NIETO MARTíN y las "multas en beneficio de la comunidad" en: NIETO MARTín, A: "Empresas ...", ob. cit, pp. 323 y ss,
} 
comprometerían seriamente las expectativas de reparación del daño de los perjudicados por el delito, sino que, incluso, los trabajadores y proveedores de la empresa se convertirían en las nuevas víctimas del conflicto, algo que el sistema debería tratar de evitar. Como es obvio, estos perjuicios a terceros también tendrían lugar si la pena impuesta a la empresa fuera la de su disolución (art.33.7.b CP), la suspensión de sus actividades (art. 33.7.c CP), o, la obligación de clausurar algunos de sus locales (33.7.d CP) ${ }^{47}$.

Pues bien, en estos escenarios entiendo que una medida que habría podido propiciar un cierto equilibro entre los distintos intereses en conflicto sería la posibilidad de condenar a la sociedad a una pena a trabajos en beneficio de la comunidad: con aquélla se habría podido obligar a la persona jurídica a poner a disposición de la comunidad parte de sus capacidades empresariales (medios, instrumentos, personal y know how) para reparar el daño del delito, sin que esta medida tuviera porque afectar de forma negativa a los intereses de sus trabajadores y/o proveedores ${ }^{48}$. De todos modos, esta medida no está entre las consecuencias jurídicas típicas que el legislador penal decidió para las personas jurídicas y, por tanto, en nuestro sistema no es aplicable.

Ahora bien, en el campo de la delincuencia económica, y en cuanto a la cuestión de la reparación del daño ambiental cometido por las personas jurídicas, considero que las opciones que se ofrecen en el Capítulo regulador de la responsabilidad civil ex delicto, y, en particular, en el artículo 112 del Código penal, precepto que permite al Juez o Tribunal imponer una obligación de contenido reparador, son especialmente relevantes ${ }^{49}$.

En concreto, el referido precepto permite imponer sobre la empresa condenada una obligación de dar, de hacer o de no hacer algo, que, atendiendo a sus condiciones personales y patrimoniales y, a la naturaleza del daño cometido, podría decidirse por parte del Juez que debiera ser realizada directamente por

\footnotetext{
47 También señala el problema de la víctima colateral NIETO MARTíN, al referir que: "este tipo de sanciones comportan graves daños colaterales (...)": NIETO MARTíN, A: (2017) "Empresas, ..." ob.cit, pp. 318.

48 De hecho, tal y como se señala en el artículo 49 del Código penal, las penas a trabajos en beneficio de la comunidad también pueden consistir en labores de reparación de los daños causados o, de apoyo o asistencia a las víctimas en delitos de similar naturaleza al cometido.

${ }^{49} \mathrm{Al}$ respecto GARCÍA ARÁN señala que "es en el ámbito de la delincuencia económica contra intereses colectivos donde este art. $112 \mathrm{CP}$ introduce una versión de la reparación del daño digna de ser tenida en cuenta": GARCÍA ARÁN, M: "Reparación ...", ob.cit, p. 474.
} 
aquélla, sin que cupiera la ejecución a su costa. Con ello, el artículo 112 del Código penal permite, ni más ni menos, la imposición de un determinado comportamiento restaurativo "personalísimo", el cual, no podrá ser delegado ni subcontratado, todo lo contrario: deberá ser realizado personal y directamente por la empresa condenada ${ }^{50}$. Una suerte, en definitiva, de sanción reparatoria penal, cuya principal finalidad es la de obligar a restaurar el daño cometido, directa y personalmente, por parte del condenado.

Pues bien, en el campo de la delincuencia medioambiental esta herramienta reparadora puede cumplir una función restaurativa muy relevante, ya que, normalmente, para las empresas que compiten en el mercado, el mero pago de los perjuicios causados representa un mal menor en la autorepresentación del balance de coste y oportunidades y, por ello, perfectamente asumible y poco amenazador. Para ello, el Juez o Tribunal podrían esgrimir el referido precepto penal para obligar a que una determinada empresa, considerada culpable de un delito, se responsabilizara de una determinada tarea de hacer (i.e: limpiar un monte, recoger y trasladar residuos, recoger basuras, construir o reparar edificios públicos, etc.), poniendo para ello sus instrumentos, instalaciones y mano de obra, parcial y temporalmente, al servicio de la comunidad lesionada por su conducta criminal ${ }^{51}$.

En este contexto, el delito ecológico, nuevamente, me permite proponer algunos ejemplos ilustrativos. Por ejemplo: imaginemos que la empresa responsable de una promoción urbanística ilegal, desarrollada en un espacio natural especialmente protegido, el cual, además, ha quedado dañado muy sustancialmente, es condenada por un delito urbanístico en concurso con un

\footnotetext{
50 En cuanto al eventual responsable persona física, ciertamente, entiendo que en algunas ocasiones también cabría utilizarse el artículo 112 del Código penal para fomentar tareas restaurativas personalísimas, que, al final, tuvieran un contenido similar al previsto en las penas a trabajos en beneficio de la comunidad. De todos modos, evidentemente, la posibilidad prevista en el artículo 112 CP no puede convertirse en una especie de "trabajos forzados 2.0" mediante los cuales los condenados individuales se vieran obligados a trabajar coactivamente en favor de las víctimas, ni, menos, en una vía para intentar buscar la humillación pública del sujeto condenado. Para las personas físicas las tareas restaurativas personalísimas previstas en el artículo 112 del CP deben interpretarse restrictivamente: solamente como un instrumento voluntario que facilitará la reparación del daño en aquellos escenarios donde los condenados se revelasen insolventes, permitiéndoles, a su vez, intentar la suspensión de la pena si además se dieran los demás requisitos previstos en el artículo 80 del CP.

51 Se dan ejemplos de experiencias de medidas reparadoras similares en: AERTSEN, I.: "Restorative ..." ob. cit, p. 252.
} 
delito medioambiental. Aquí, para favorecer la mejor reparación, el Tribunal podría decidir que, además de las sanciones pertinentes, se condenase a la sociedad responsable del delito, a la luz del artículo 112 CP, a la obligación de restaurar el espacio físico alterado y realizar tareas de limpieza de montes y/o trabajos de conservación forestal en favor de la comunidad atacada por el delito cometido.

Además, y si bien considero que las capacidades preventivo-generales de las medidas que posibilita el artículo 112 del CP (al menos de carácter simbólico ${ }^{52}$ ) son evidentes, su justificación aplicativa no se agotaría en aquéllas, también alcanzaría a temas vinculados con la prevención especial positiva en los delitos de cuello blanco. Me explico: se ha dicho por parte de la doctrina que, en el fenómeno de la gran delincuencia socioeconómica, los responsables, como normalmente no conocen directamente a las víctimas de sus decisiones, ni el alcance real de los perjuicios causados, son propensos a minusvalorar el daño potencial de sus acciones. Así, a diferencia de la delincuencia tradicional, donde el victimario puede ser perfectamente consciente del daño materialmente infligido a la víctima, en la delincuencia socioeconómica colectiva en general, y en escenarios de delitos medioambientales en particular, los responsables de las empresas contaminantes no llegan a conocer los perjuicios materiales concretos que sus decisiones empresariales han causado sobre un número indeterminado de conciudadanos. Al respecto, por ejemplo, GARCÍA ARÁN recuerda que el delincuente socioeconómico tiende a despersonalizar a las víctimas cuando éstas son colectivas y/o indeterminadas "lo que favorece la autojustificación del infractor ante la víctima desconocida ${ }^{53 " .}$

Por todo ello, considero que a través del instrumento reparador previsto en el artículo 112 del Código penal, el Juez o Tribunal podría fomentar que los delincuentes socioeconómicos se enfrentaran a una pequeña parte del resultado lesivo que sus acciones habrían provocado (o habrían podido provocar, como ocurriría en los delitos intentados o los delitos de peligro abstracto sin resultado

\footnotetext{
${ }^{52}$ En este sentido TAMARIT señala que debería aceptarse la reparación simbólica y/o inmaterial como forma legítima de reparación del daño: TAMARIT SUMALLA, J.M: "La difícil asunción de la reparación penal por la jurisprudencia española", Revista General de Derecho Penal, lustel, núm. 7, 2007, pp. 15 y 16.

${ }^{53}$ GARCÍA ARÁN, M: "Reparación ...”, ob.cit, p. 454.
} 
lesivo consumado). Con ello, quizá, se podría intentar motivar algún cambio comportamental (al menos en los miembros del órgano de administración de la sociedad), que, al final, fuera relevante para determinar las expectativas preventivo-especiales de la empresa condenada. De lo que se trataría, aquí, es de que los responsables de la empresa fuesen capaces de interiorizar y entender que el sistema penal no les ha castigado por contradecir una fría norma penal, se le ha sancionado por haber atacado un interés colectivo digno de protección penal y, con ello, haber causado un perjuicio medioambiental perfectamente real ${ }^{54}$.

En definitiva, considero que condenar a las empresas penalmente responsables a determinadas funciones reparadoras del daño ecológico cometido serviría tanto para reforzar la confianza del grupo social en el sistema penal como, para mejorar las expectativas preventivas en la delincuencia empresarial, la cual, se ha constatado que, ante la víctima desconocida, o ante bienes jurídicos intangibles, suele ignorar (quizás deliberadamente) los efectos potencialmente lesivos de sus acciones criminales.

Por todo lo anterior, considero que el artículo 112 del Código penal se revela como un instrumento restaurativo muy significativo, especialmente cuando se quiera obligar a las empresas penalmente responsables a que se responsabilicen y reparen, directa y personalmente, los graves daños medioambientales provocados por sus acciones criminales.

\section{ALGUNAS MEDIDAS REPARADORAS PREVISTAS EN LA PARTE ESPECIAL DEL CÓDIGO PENAL}

Antes de cerrar el presente trabajo entiendo que son necesarias algunas consideraciones finales sobre las previsiones reparadoras ecológicas contenidas en la parte especial del Código penal.

\footnotetext{
${ }^{54}$ En este sentido, por ejemplo, GASCÓN INCHAUSTI señala que con la justicia restaurativa "se propone la implantación de un sistema de justicia penal que tenga un valor "restaurativo": que sirva para una eficaz reparación a la víctima y para que el autor del delito sea consciente de su responsabilidad y de las consecuencias de sus actos": GASCÓN INCHAUSTI, F: (2019-2020) Derecho procesal penal, materiales para el estudio, Universidad Complutense de Madrid, p. 28.
} 
En este sentido, por ejemplo, en el artículo 340 del Código penal se señala que, si el culpable de un delito ecológico procede, voluntariamente, a reparar el daño causado, se le impondrá la pena rebajada en un grado. Esta atenuante específica puede fomentar comportamientos reparadores "espontáneos" que favorezcan la pronta reparación del daño ecológico causado. De todos modos, para la aplicación de esta atenuante no solamente debe exigirse que la conducta restaurativa esté específicamente dirigida a reparar el daño ecológico causado, sino que, además, aquélla sea plenamente idónea para ello. Así, las técnicas de reparación empleadas deben ser potencialmente efectivas, lo que comporta, evidentemente, que las tentativas reparadoras inidóneas o espurias no pueden activar la atenuante prevista en el artículo 340 CP55.

Ahora bien, en aquellos escenarios donde el autor del delito no procediese voluntariamente a reparar el daño (escenarios por otro lado recurrentes), los órganos judiciales penales también podrían utilizar el artículo 339 del CP, precepto que señala que los jueces o tribunales ordenarán, a cargo del autor del hecho, las medidas que sean necesarias para restaurar el equilibrio ecológico perturbado.

Al respecto, en cuanto a su naturaleza, esta medida no puede considerarse una pena, ya que ésta: (i) no está incluida en el listado general de penas previsto en el artículo 33 del Código penal; y, además, (ii) a través de una interpretación teleológica puede llegarse a la conclusión de que en el artículo 339 CP se busca principalmente la reparación del daño, todo ello en la línea marcada en el artículo 110.2 del Código penal sobre la reparación civil ex delicto prevista en la parte general del Código penal.

De todos modos, la doctrina mayoritaria entiende, a mi juicio acertadamente, que pueden encontrarse argumentos acerca de una cierta naturaleza híbrida de esta medida, situándola a caballo entre la sanción penal y la reparación civil. Por ejemplo, GARCÍA ARÁN señala que del hecho de que las medidas previstas en el artículo $339 \mathrm{CP}$ tengan que ser sufragadas directamente por parte del

\footnotetext{
55 En este orden de cuestiones, también pueden plantearse incidentes concursales entre la atenuante específica prevista en el artículo $340 \mathrm{CP}$ y la atenuante genérica de reparación señalada en el artículo 21.5 CP. En este sentido, y a la luz del criterio de especialidad, entiendo que en escenarios de delitos ecológicos debe apostarse por la atenuante prevista en el artículo $340 \mathrm{CP}$.
} 
condenado, impidiéndose con ello el pago por parte de terceros, "se despende la pretensión de imponer al responsable penal una carga, personal e intransferible, restauradora de la situación perturbada que, además, se concreta en actuaciones específicas recayentes sobre el bien dañado, distintas del mero pago de una cantidad indemnizatoria ${ }^{56 " . ~ E n ~ e l ~ m i s m o ~ s e n t i d o ~ t a m b i e ́ n ~}$ BAUCELLS LLADÓS señala que estos preceptos "contienen, en realidad, sanciones reparadoras dirigidas a beneficiar a la colectividad en situaciones en que es difícil identificar perjudicados individuales ${ }^{57 "}$.

Como puede observarse, el contenido reparador previsto en el artículo 339 CP se asemeja a lo dispuesto en el artículo 112 CP (precepto comentado supra), pero, con una relevante nota diferencial: la reparación prevista en el artículo 339 CP tiene un contenido patrimonial intransferible (la reparación del daño debe ser "pagada" por el condenado) pero, no pasa por ser una obligación de hacer "personalísima" (como sí se permite en el artículo 112 CP, con cuyo redactado el juez penal puede imponer obligaciones de hacer, de contenido reparador, que hayan de ser cumplidas directamente por el autor del hecho criminal).

De todos modos, en aquellos escenarios donde se consumen ataques contra el medioambiente, la medida prevista en el artículo 339 del Código penal también ayudará a una mejor reparación del daño cometido, propiciando la restauración de los bienes jurídicos medioambientales atacados a costa del patrimonio del condenado ${ }^{58}$.

\section{CONCLUSIONES}

Como se ha dicho al principio, en la actualidad no contamos con una conceptualización única de lo que debe considerase justicia restaurativa. De todos modos, algunos presupuestos cuentan con una aceptación doctrinal general. Así, las ideas de restauración de las relaciones sociales lesionadas, la

\footnotetext{
${ }^{56}$ GARCÍA ARÁN, M: "Reparación ...", ob.cit, p. 479.

57 BAUCELLS LLADOS, J: en CÓRDOBA RODA/ GARCÍA ARÁN (directores) Comentarios al Código Penal. Parte Especial, I, Marcial Pons, Madrid, 2004, p. 1475.

58 En esta línea, en la Sentencia del Tribunal Supremo 521/2015, de 13 de octubre, se ha señalado que: "Es remedio prioritario la reparación (entendida como restauración o reposición al estado anterior) a costa del infractor. A esa medida se refiere concretamente el artículo $339 \mathrm{CP}$ (tutela reintegradora), acogiendo el más reciente estándar en materia de medio ambiente: el que contamina, restaura, que ha desplazado a un segundo plano al clásico el que contamina paga".
} 
pacificación comunitaria y, la reparación de los perjuicios injustamente soportados por las víctimas, son algunos de los objetivos mínimos que justifican los proyectos de justicia restaurativa.

En el campo de la delincuencia tradicional, donde, normalmente, víctimas y victimarios estarán identificados, las corrientes de justicia restaurativa podrán utilizar los encuentros participativos para facilitar algún tipo de acuerdo reparador. En cambio, atendiendo a la idiosincrasia de los delitos contra el medioambiente, tipos penales con bienes jurídicos colectivos y posibles resultados lesivos sobre víctimas difundidas, las corrientes de justicia restaurativa, en ocasiones, deberán buscar apoyo en otros instrumentos jurídicos que les permitan alcanzar la mejor reparación comunitaria posible.

Por ello, en este artículo he defendido que, con el fin de mejorar el sistema de reparación y restauración, al menos en el campo de la delincuencia ecológica, podrían utilizarse las penas económicas, el decomiso y, la responsabilidad civil ex delicto "personalísima" para, a partir de una nueva mirada de justicia restaurativa, ayudar a completar la reparación y/o restauración del daño producido por el delincuente medioambiental.

En este sentido, en cuanto a las penas económicas y el decomiso, la idea es simple: se trataría de destinar parte del dinero obtenido a través de estos instrumentos penales para, desde una nueva mirada de justicia restaurativa, propiciar una reparación más completa del espacio natural o interés ecológico lesionado. En concreto, tanto con los ingresos obtenidos a través de las penas pecuniarias, como con los obtenidos después de la ejecución de un decomiso, se podrían financiar todo tipo de políticas públicas restaurativas, las cuales, podrían servir tanto para reparar directamente los daños materiales generados por el delito, como, para mejorar la tutela futura del bien jurídico puesto en peligro.

Finalmente, también he señalado que gracias al artículo 112 del Código penal se pueden imponer, sobre la empresa condenada, obligaciones de hacer que no se puedan "subcontratar", las cuales, a mi juicio, al menos en el campo de la justicia restaurativa, pueden servir tanto para satisfacer cuestiones vinculadas con la prevención general (a través de la restauración, cuanto menos simbólica, del bien jurídico lesionado), como, con la prevención especial (a través de la 
concienciación de la condenada, al menos intentada, respecto del daño realmente cometido por aquélla). Así, y considerando muy especialmente que la pena a trabajos en beneficio de la comunidad no está prevista como consecuencia jurídica para las personas jurídicas, las cuales, representan el mayor foco de peligro en el campo de la protección medioambiental, pienso que, como mínimo, debería explorarse el alcance del artículo 112 del Código penal para restaurar los daños cometidos en el campo de la delincuencia empresarial en general y, de los tipos penales ecológicos en particular.

Ciertamente las propuestas señaladas en las páginas anteriores no encajan con algunos de los adjetivos de la justicia restaurativa más purista, en especial el carácter voluntario de la participación del agresor en el procedimiento restaurador y la necesaria reivindicación de la víctima como sujeto decisorio. Ahora bien, si queremos ampliar el alcance real de las ideas de justicia restaurativa a otros campos criminales, más complejos que los diseñados en las primeras formulaciones deberemos permitir una moderación de las líneas rojas de los sistemas de justicia restaurativa más ortodoxos.

En definitiva, cuando queramos asegurar la mejor reparación y restauración posible del bien jurídico protegido en los delitos medioambientales, deberemos acomodar los principios de la justicia restaurativa a las características de los tipos penales ecológicos, tipos penales complejos con bienes jurídicos colectivos y víctimas difundidas, donde, a mi juicio, las penas de multa, el decomiso y, la responsabilidad civil ex delicto "personalísima" nos ofrecen una ayuda que no podemos despreciar, ayuda que, además, no compromete el siempre necesario carácter público de la relación jurídico-penal entre el Estado y el criminal, cuestión que aquí aprovecho para reivindicar como una de las conquistas irrenunciables del sistema jurídico-penal liberal.

\section{BIBLIOGRAFÍA}

AERTSEN, I: "Restorative justice for victims of corporate violence", en FORTI, G. (Ed.): Victims and corporations. Legal Challenges and Empirical Findings, Milano, Wolters Kluwer, CEDAM, 2018. 
AGUdO FERnÁNDEZ, E/ PERRINO PÉREZ, A/ JAÉN VALLEJO, M: Penas, medidas y otras consecuencias jurídicas del delito, Madrid, Dykinson, 2017.

ALASTUEY DOBÓN, C: La reparación a la víctima en el marco de las sanciones penales, Valencia, Tirant lo Blanch, 2000.

BARONA VILAR, S: Mediación penal. Fundamento, fines y régimen jurídico. Valencia, Tirant lo Blanch, 2011.

BAUCELLS LLADOS, J: en CÓRDOBA RODA/ GARCÍA ARÁN (directores) Comentarios al Código Penal. Parte Especial, I, Madrid, Marcial Pons, 2004.

BOLIVAR, D: "Conceptualizing victims restoration in restorative justice", en International Review of Victimology, 2010.

BRAITHWAITE, J: Crime, Shame and Reintegration, New York, Cambridge University Press, 1989.

BUSTOS RAMíREZ, J: Prevención y Teoría de la Pena, Santiago de Chile, Editorial Jurídica Conosur, 1995.

CHRISTIE, N: "Conflicts as Property", en The British Journal of Criminology, 1977.

CÓRDOBA RODA, J/ GARCÍA ARÁN, M (directores): Comentarios al Código penal, Parte general, Barcelona, Marcial Pons, 2011.

DANIELS, G: "Restorative justice: Changing the paradigm" en Probation Journal, The Journal of Community and Criminal Justice, 2013.

DÍAZ CABIALE, J.A: "El decomiso tras las reformas del Código penal y la Ley de Enjuiciamiento Criminal de 2015", en Revista Electrónica de Ciencias Penal y Criminología, 2016.

DOMINGO DE LA FUENTE, V: "Justicia restaurativa como ciencia penal o social, encaminada a mejorar la justicia" en Revista Educació Social. Revista d'Intervenció Socioeducativa , N.67, 2017.

DURÁN MIGLIARDI, M: "Teorías absolutas de la pena: origen y fundamentos. Conceptos y críticas fundamentales a la teoría de la retribución moral de Immanuel Kant a propósito del neo-retribucionismo y del neo-proporcionalismo 
en el Derecho penal actual", en Revista de Derecho y Ciencias Penales №16 (91-113), 2011.

FORTI, G/ MAZZUCATO, C/ VISCONTI, A/ GIAVAZZI, S: Victims and Corporations, Legal Challenges and Empirical Findings, Wolters Kluwer, 2018.

G. W. F. HEGEL: Principios de la filosofía del derecho o Derecho natural y ciencia política, ed. Edhasa, (1821) 2º edición 1999.

GABBAY, ZVI. D: "Exploring the Limits of the Restorative Justice Paradigm: Restorative Justice and White-Collar Crime", en Cardozo School of Law Journal of Conflict Resolution, 2012.

GARCÍA ARÁN, M: "Reparación a la víctima y mediación en la delincuencia económica", en Un Derecho penal comprometido, libro homenaje al Dr. Gerardo Landrove Díaz, Valencia, Tirant Lo Blanch, 2011.

GORDILLO SANTANA, L.F: La justicia restaurativa y la mediación penal, lustel, Madrid, 2007.

JOHNSTONE G/ W. VAN NESS, D: "The meaning of restorative justice", en JOHNSTONE, G and VAN NESS, D (editores).: A Restorative Justice Reader. Text, sources, context, Willan Publishing, 2007.

KANT, I: La metafísica de las costumbres (Título original Metaphysik der Sitten), 1797.

KATHLEEN DALY: "Restorative justice, The real story", en Punishment \& Society, 2002.

LARSON, J/ HOWARD, Z: "The ideas of engagement and empowerment", en JOHNSTONE, G, Handbook of Restorative Justice, Ed. Willam Publising, 2007.

LEMLEY ELLEN C: "Designing Restorative Justice Policy: An Analytical Perspective", en Criminal Justice Policy Review, Vol.12, Number 1, March, 2001. MAGLIONE, G: "The political rationality of restorative justice" en, Theoretical Criminology, 2019

MARTÍNEZ-ARRIETA MÁRQUEZ DE PRADO: El decomiso y la recuperación y gestión de activos procedentes de actividades delictivas, Valencia, Tirant Lo Blanch, 2018. 
MARTÍNEZ ESCAMILLA, M: "La mediación penal en España: estado de la cuestión", en, Justicia restaurativa, mediación penal y penitenciaria: un renovado impulso, Editorial Reus, Madrid, 2011.

MIR PUIG, S: Derecho Penal, Parte General, Barcelona, Editorial Reppertor, 2016.

MIZRAHI, E: “La legitimación hegeliana de la pena”, en Revista De Filosofía, Vol. 29, Núm. 1, 2004.

MYERS, D/ OLSON, J: "Restorative Justice and Community Corrections", en Criminal Justice Policy Review, 2015.

NIETO MARTÍN, A: "Autorregulación, "compliance" y justicia restaurativa”, en ARROYO JIMÉNEZ, L; NIETO MARTíN, A (Dir.): Autorregulación y sanciones, Aranzadi, Navarra, 2015.

NIETO MARTÍN, A: “Empresas, víctimas y sanciones restaurativas: ¿Cómo configurar un sistema de sanciones para personas jurídicas pensando en sus víctimas?", en HOYOS SANCHO, M. La víctima del delito y las últimas reformas penales, Aranzadi, Navarra, 2017.

PAUL McCOLD: "Paradigm Muddle: The Threat to Restorative Justice Posed by Its Merger whit Community Justice", en, Contemporary Justice Review, Vol 7, 2004.

RODRÍGUEZ PUERTA, MJ: "Modelos de prevención y sanción de la delincuencia económica. Perspectiva comparada", en La delincuencia económica. Prevenir y sancionar, GARCÍA ARÁN, M (Dir.) Valencia, Tirant lo blanch, 2014.

ROXIN, C: "Sentido y límites de la pena estatal" en Problemas básicos del Derecho Penal, Madrid, Ed. Reus, 1976.

ROXIN, C: Derecho Penal. Parte General, Madrid, Civitas, 2006.

SHAPLAND, J: "Implications of growth: Challenges for restorative justice", en International Review of Victimology, 2014.

SOLETO, H/ GRANÉ A: La reparación económica a la víctima en el sistema de justicia, Madrid, Dykinson, 2019. 
SPALDING, ANDREW, B: "Restorative Justice for Multinational Corporations", en Ohio State Law Journal, 2015.

TAMARIT SUMALLA, J.M: "La difícil asunción de la reparación penal por la jurisprudencia española", Revista General de Derecho Penal, lustel, núm. 7, 2007.

TAMARIT SUMALLA, J.M: "La justicia restaurativa: concepto, principios y marco teórico", en Tamarit (Coord.) La justicia restaurativa: desarrollo y aplicaciones, Granada, Comares, 2012.

TAMARIT SUMALLA, J.M: "EI necesario impulso de la Justicia restaurativa tras la Directiva europea de 2012", en Ars luris Salmanticensis, Volumen 1, 139-160, 2013.

WALGRAVE, L: "La justice restaurative et les víctimes", Le Journal International de Victimologie, 2002.

WALGRAVE, L: "Integrating criminal justice and restorative justice", en JOHNSTONE, G./ VAN NESS and VAN NESS, D (editores): Handbook of Restorative Justice, Willan Publishing, 2007.

WALGRAVE, L: "Investigating the Potentials of Restorative Justice Practice", en, Washington University Journal of Law \& Policy, 2011.

ZEHR, H: "Retributive Justice, Restorative Justice", en New Perspectives on Crime and Justice, Occasional paper of the MCC Canada Victim Offenders Ministries Program, 1985.

ZEHR, H: Changing lenses: a new focus for Crime and Justice, Scottsdale, PA, Herald Press. 1990.

ZEHR, H/ GOHAR, A: (2003) The little book of Restorative Justice, Good Books. 